\title{
The approach to comprehensive assessment of the regional agro-food industry development problems
}

\author{
$A Q$ Jalal $^{1}, Z A$ Izotova $^{1, *}$, and $G I$ Ivanov $^{1}$ \\ ${ }^{1}$ Crimean Federal University named after V.I. Vernadsky, 295007, Akademika Vernadskogo Avenue, \\ 4, Sevastopol, Russia
}

\begin{abstract}
The study is devoted to the development of approach to comprehensive assessment of the regional agro-food industry development problems. This task was solved using the methods of expert assessment and statistical analysis of their results. We have substantiated a system of agro-food industry development indicators, which covers the level of enterprises and the level of government. Approbation of the proposed approach using the example of the Republic of Crimea revealed the key problems. At the enterprise level: low level of development of advanced technologies, low share of innovative products, ineffective organization of cause-and-effect analysis, insufficient scientific feasibility of technological processes. At the state level: insufficiently effective state regulation in the field of import substitution, insufficient stimulation of demand for domestic products of the processing industry of the agro-industrial complex (AIC), insufficient state stimulation of the production of highquality domestic products, insufficient level of scientific research support. This allows determining the priority directions for the development of recommendations and the implementation of actions to ensure the regional agro-food industry development.
\end{abstract}

\section{Introduction}

One of the conditions for ensuring the regional agro-food industry development is the availability of an appropriate system of indicative criteria to assess its level, which makes it possible to predict the direction of the regional production socio-economic development.

The use of an indicative approach makes it possible to implement proactive measures by focusing on the established relationships between indicators, which serve as the development direction regulation tools at the same time.

Operating only with monetary criteria narrows the information base, complicates formation of the holistic view of the research object status. In addition, cost indicators are lagging (deferred indicators). According to modern concepts, a complete and objective assessment of the development level of such a multidimensional research object as the

\footnotetext{
* Corresponding author: zoia.zoya@gmail.com
} 
regional agro-food industry is impossible without taking into account the social criteria and conditions that ensure the achievement of future financial results.

This study is aimed at the development of approach to comprehensive assessment of the regional agro-food industry development, taking into account the parameters lying in two influence fields - enterprises and government.

Our analysis of recent publications has shown that this direction is highly controversial.

Numerous studies have been focused on identifying appropriate indicators to assess sustainability in the field of agro-food industry assessment. Their number varies from a few to more than a hundred indicators seeking to cover all sustainability aspects - Singh study [1]. For example, FAO and RUAF (Holland), affiliated with the Center for Sustainable Food Systems at the Wilfried Laurier University (Canada), have developed a set of indicators to assess the agro-food industry sustainability in the region.

Reliable analysis and evaluation methods are widely used, including "use-oriented evaluation" - Patton study [2]. However, the papers devoted to the relationship between food systems and holistic sustainability are sparse (such as Aubin [3]) and virtually nonexistent in relation to social innovation and pathways. Popov [4] used a quantitative approach to measure the impact of social innovation on the agro-food industry development. Dhondt et al. [5] developed a socio-economic impact analysis. Wiek et al. [6] use logarithmic modeling to analyze the development experiments in cities that integrate the transition to sustainability by forming the basis for the scoring scheme by Luederitz et al. [7]. Luederitz specifically studied the Urban Sustainability Transition Laboratories (USTL) and used the logarithmic models to assess both the site-specific and city-wide USTL outcomes. The studies also looked at whole agro-food systems (Institute of Medicine and National Research Council, 2015), but local agro-food initiatives were not taken into account.

Multiple assessment approaches rely on standardized, expert and quantitative data collection, as well as analysis tools to ensure comparability, reproducibility, and objectivity. For example, such methods are used in such areas as agriculture, health and water management - Peterson study [8], based on the assumption that they provide enough data and recommendations to make objective and scientifically sound decisions - Leach studies [9]. On the other hand, Naudet [10] argues that quantitative and financial evaluations ignore critical elements, emphasizing their inability to establish a causal relationship that allows evaluating the development policy or any project.

Aubin et al. [3] carried out a critical review of approaches to assess the agro-food industry sustainability and their applicability, consisting of general methods ranging from life cycle assessment (LCA); such economic methods as cost benefit analysis (CBA); retrospective assessment of food and resource use; physical and synthetic indicators of environmental stress; nutritional and epidemiological approaches; approaches to assess barriers and incentives to sustainable consumption; summary social and ethical indicators; as well as multi-criteria and joint assessment tools. Their main criticism is that the prevailing approaches and methods are too global (input-output analysis); too local (LCA); too one-dimensional (physical and synthetic indicators); too static (LCA, economic methods, physical and synthetic indicators); have too predictable and narrow methodology (LCA); too imprecise (LCA); require data that is difficult to obtain (input-output); vulnerable to errors (input-output); or too focused on macronutrients (food availability) and consumer motivation (assessment of sustainable consumption); or neglect the informal economic trade (input-output). The latter problem is especially relevant for the developing countries. At the same time, Aubin [3] rejects qualitative or context-specific elements or, for example, in case of cost benefit calculations, underestimates potential future dynamics Howarth \& Norgaard studies [11] in favor of being focused on the current value streams - 
Portney \& Weyant studies [12]. Finally, while being focused on the effect measuring methods, they do not pay enough attention to causal relationships - Mayne studies [13].

However, these are time-consuming and costly approaches that cannot be easily used by the local authorities or innovators to better justify their decisions and actions under a tight budget. This forces many politicians to make plans without a clear idea of what impact they can have and what result they will achieve. For these reasons, it is necessary to explore simpler and collaborative approaches that can promote social learning in the context of public policy.

The development presented in the Brundtland report (World Commission on Environment and Development, 1987) has significantly influenced the requirements and development of assessment tools that have to deal with the contextual (site-specific conditions), transient (impacts occurring in different, often long time after the intervention), and multidisciplinarity problems - Temple studies [14]. Based on these considerations, new and better approaches to assessing sustainability have been proposed to help manage the agro-food industry. Some approaches to determine the appropriate resilience metrics range from expert-led selection to broader participatory processes that help communities define their own metrics - Fraser [15], Abi-Nader studies [16]. For example, Landert [17] developed a joint process for the implementation of the Guidelines for the Sustainability Assessment of Food and Agriculture Systems (SAFA) of the Food and Agriculture Organization (FAO). The multicriteria assessment approach uses 97 indicators, scoring 51 of the SAFA subtopics. The indicators are selected based on an integrated approach to assessment of a sustainable agro-food industry and is based on the policies and measures related to the urban agro-food system processes. Carlsson [18] proposed a collaborative methodology based on the Framework of Strategic Sustainable Development (FSSD) through a modified Delphi query process to identify the key indicators to track progress towards the agro-food system success at the local level. The implementation of such approach was made possible due to the data availability in both Landert [17] and Carlsson [18]. Two improvements to these approaches should be noted. Firstly, data availability cannot be guaranteed in the in developing countries. Secondly, in both cases, the approaches are aimed at assessing and improving the entire agro-food industry and its sustainability, rather than promoting and improving the local innovation. Finally, although several research groups have studied the impact of development innovations on the agrofood system, they often limit the assessment to one or two sustainability dimensions: environmental issues (using LCA tools) and/or nutrition issues (using consumption surveys). The interactions between sustainability aspects have rarely been taken into account. To better fill this gap, several assessment approaches use collaborative mapping to identify and explore the impact of innovation - Douthwaite [19], Proietti [20] studies. URBAL is following this path.

\section{Materials and methods}

Since the development of the regional agro-food industry cannot be directly quantified, it is advisable to use the expert assessment method to obtain an adequate idea of the qualitative state of the research object. The specified task is implemented according to the algorithm (fig. 1).

A reliable assessment of the regional agro-food industry development requires the identification of a wide range of its essential features at the micro and macro levels with the determination of their attainable reference values, which constitutes a criterion assessment system. In compliance with the interconnection and adaptability requirements, we have formed the systems of indicators that diversify the development level and take into account the industry specificity of business processes (fig. 2-3). 
The proposed set of indicative evaluation criteria is consistent with the key international principles of quality and safety management of agro-food products, thereby making it possible to objectively position the regional agro-food industry in the context of global competition.

The regional agro-food industry enterprises are a simple unit that determines the AIC processing industry development in the region.

In order to comprehensively assess the problematic issues of the regional agro-food industry development and develop sound recommendations to increase its level, there is an objective need for a detailed study of processes at the micro level according to the author's concept.

A chain of interrelated and interdependent management decisions is taken at the level of an individual enterprise - from drawing up the strategic and short-term development plans to determining and analyzing the actual results of their implementation.

In this regard, the provision of relevant information with the sufficiency, reliability and efficiency parameters is of particular importance. Effective management decisions should be based on the quality control and product safety data, calculation and reflection of costs and benefits in accordance with the management accounting regulations adopted at the enterprise, as well as monitoring data of external conditions.

The existing interrelationships serve as prerequisites for the allocation of development planning indicators for the agro-food industry enterprises and their competitive advantages into separate blocks, as well as information and analytical support for the decision-making and control over the achievement of target development indicators. 


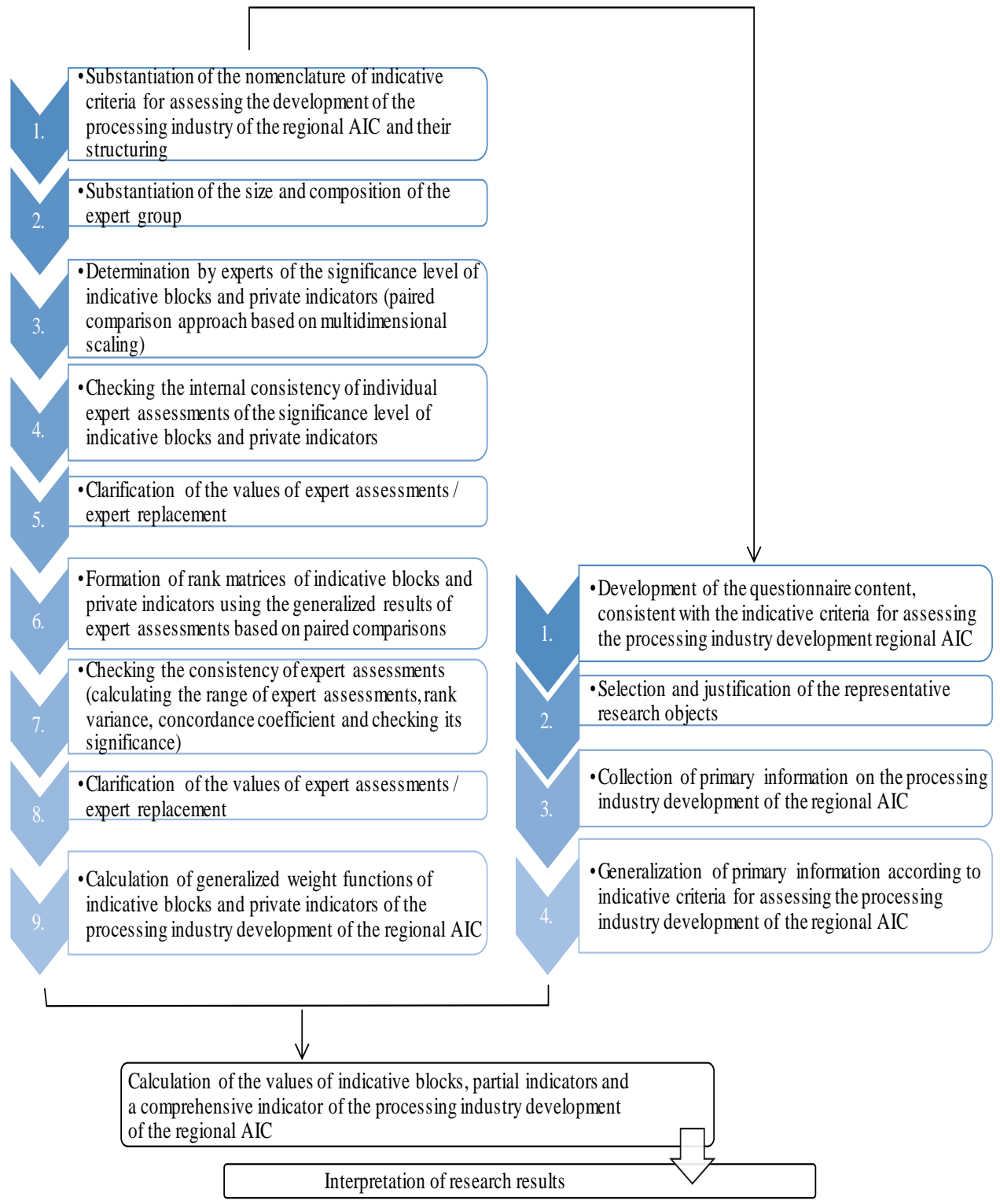

Fig. 1. Algorithm for calculating a complex indicator of the regional agro-food industry development.

The organization of development management processes is inextricably linked with the organization of effective functioning of the employees, designed to ensure the interaction of various structural units, participants in business processes, labor means and objects to achieve target indicators. In this regard, the comprehensive assessment system of the regional agro-food industry development should include an indicative block to organize the technological processes and a block of indicators to ensure labor efficiency. 


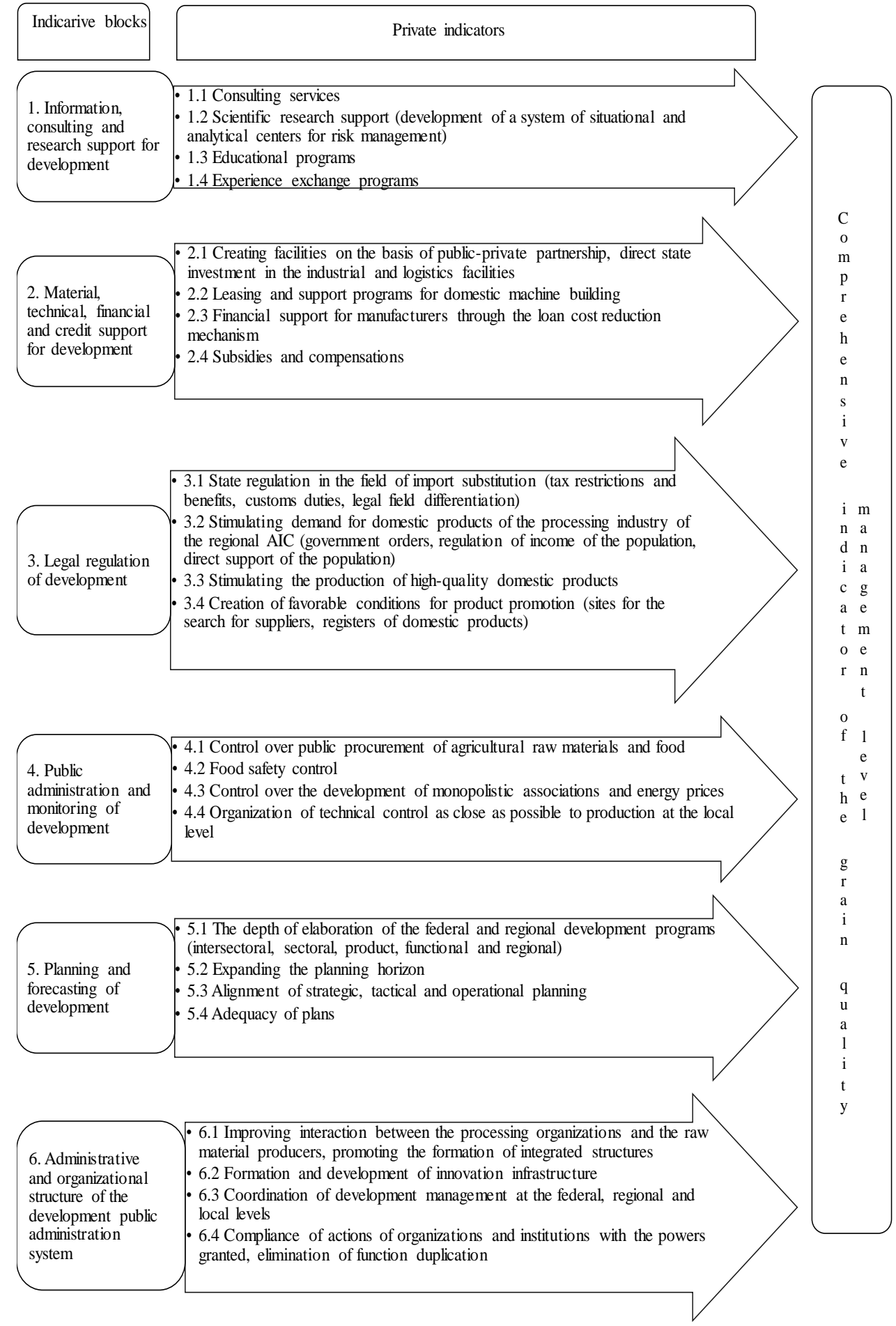

Fig. 2. The system of indicators to assess the development of the regional agro-food industry enterprises. 
Each of five blocks is formed as a result of additive folding of the list of subordinate hierarchy level indicators, which forms an integral development indicator of the regional agro-food industry enterprises in general, which takes into account the different significance of particular indicators and indicative blocks formed from them.

The mechanism for determining the weight parameters of indicative blocks and private indicators presupposes the involvement of a group of competent experts, the number of which was established according to the statistical approach. To calculate the required and sufficient number of experts, the following formula is used:

$$
N=\frac{t_{\alpha}^{2}}{\varepsilon_{1}}
$$

where $t_{\alpha}^{2}$ - confidence indicator for the accepted confidence level of the desired result; $\varepsilon_{1}$ - maximum permissible error (in fractions of the standard deviation).

At a confidence level $\alpha=0.95$, taking $\varepsilon_{1}=0.5$, the required number of experts is seven. The size of the expert group, calculated using statistical values, does not contradict the requirements of the approach limiting the upper and lower bounds for the size of the expert group. According to the research results by Beshelev [21], it is advisable to take the upper limit at the level of 10 people, while the lower threshold value $N_{\min }$ should satisfy the condition $\mathrm{N}_{\text {min } \leq \mathrm{m}}$, where $\mathrm{m}$ is the number of evaluated elements. In our case, taking into account the requirement of the same representation in assessing various structural elements of the integral indicator of the regional agro-food industry development, $\mathrm{m}=5$, therefore, a group of respondents, including seven competent specialists, consisting of the representatives of the Ministry of Agriculture of Crimea, its subordinate organizations, faculty composition of the Federal Autonomous Educational Institution of Higher Education "Crimean Federal University named after V.I. Vernadsky", managers and specialists of enterprises, satisfies the condition $\mathrm{N}_{\min } \leq \mathrm{N} \leq \mathrm{N}_{\max }$.

The significance of indicators was compared using a matrix of paired comparisons under the Saati recommended scale of relative importance [22]. This approach involves asking the experts the question: "To what extent does the significance of one indicator exceed the significance of the other in ensuring the regional agro- food industry development?" The subsequent calculation of the weight factor vector requires calculation of the geometric mean values for each matrix row, the sum of which is the basis for calculating the specific weights of the corresponding private indicators or their blocks as part of the integrated indicator of the regional agro-food industry development.

It should be noted that the range of estimates and their variance characterize only the individual structural elements of the integrated development indicator of regional agro-food industry enterprises. A generalized assessment of the consistency of expert opinions on a set of indicators can be obtained by calculating the concordance coefficient:

At the first stage, an ordered sample matrix is compiled for the mean rank values, on the basis of which the modified concordance coefficient is calculated using the formula:

$$
K_{\text {кон } M}=\operatorname{tg} g_{\alpha}=\frac{\sum_{i \leq j}\left(M_{j}-M_{i}\right)}{\sum_{i \leq j}\left(Y_{j}-Y_{i}\right)}
$$

where $\sum_{i \leq j}\left(M_{j}-M_{i}\right)$ - cumulative difference of the mean values in ascending order; 
$\sum_{i \leq j}\left(Y_{j}-Y_{i}\right)$ - cumulative difference of the ranks in ascending order.

The statistical significance of the studied relationship between the ranked series may be assessed based on the Pearson Chi-squared test, which does not depend on the type of distribution.

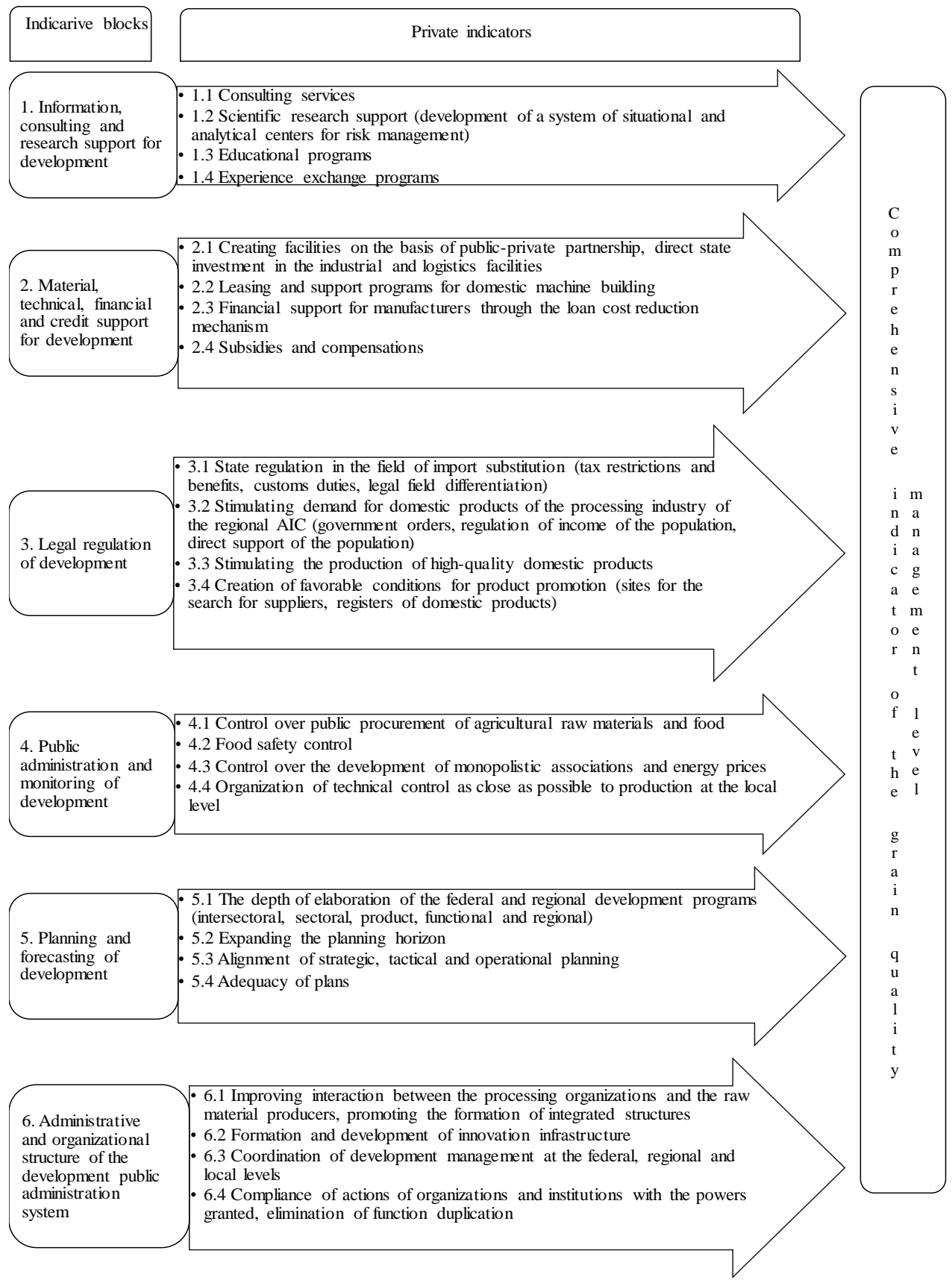

Fig. 3. The system of indicators to assess the public administration of the regional agro-food industry development. 
In our case, with a normal distribution of the general population, when the mathematical expectation and the standard deviation parameters are considered, the number of freedom degrees is calculated using the formula $\mathrm{k}=\mathrm{n}-3$ (with the number of distribution parameters $\mathrm{z}=2$ ) (Gmurman [23-25]). Then the empirical value of the Chi-squared test is determined by the equality:

$$
X_{\ni}^{2}=m(n-3) K_{\text {онм }}
$$

The excess $X_{\ni}^{2}$ over the theoretical (tabular) value indicates significance of the concordance coefficient.

Further, the particular indicators and their groups are ranked based on the average expert assessments, and an integral vector of priorities, which makes it possible to judge the influence degree of individual structural elements of the system on the development of regional agro-food industry enterprises, is built based on the generalization results.

The calculation data are used to calculate the weight functions of the structural elements as part of a complex indicator according to the formula $Q_{i}=\left(1 / M_{i}\right) / \sum\left(\frac{1}{M_{i}}\right)(4)$, where $\mathrm{M}_{\mathrm{i}}$ mean value.

At the next stage, the importance degree of the indicative blocks is generalized with the specific weights of the particular indicators forming them. The criteria hierarchy is synthesized by multiplying the indicator vectors by the priority of their group.

Further, it is necessary to single out those features of the development level of regional agro-food industry enterprises, whose improvement will be the most resonant for the system and will lead it to a relatively stable position.

The criterion for assessing the problem priority is $\mathrm{H}_{\mathrm{i}}$ value, calculated according to the formula:

$$
H_{i}=\left(10-V_{i}\right) P_{i}
$$

where $V_{i}$ - the generalized expert assessment value of the $i$-th feature of the development of processing enterprises of regional AIC;

$\mathrm{P}_{\mathrm{i}}$ - the level of relative importance of the $\mathrm{i}$-th features in the indicator system (taking into account the group priority).

The greater value of $\mathrm{H}_{\mathrm{i}}$ coefficient of a certain features determines the primary need to concentrate efforts on its improvement.

Determination of the priority number of indicators of the public administration level of the regional agro-food industry development and assessment of its current state were carried out in a similar way to the calculation of the corresponding indicators of the regional agro-food industry enterprises.

The system of indicators to assess the public administration of the regional agro-food industry development is presented in fig. 2 .

\section{Results}

The formation of a ranked series of weight coefficients based on the assessment results of one of the expert group members is presented using the example of indicative development blocks of the regional agro-food industry enterprises (Table 1). The priority vectors of each of the survey participants and of the structural elements of the blocks under study are calculated accordingly. In Table 2, the values of individual priority series of the expert group representatives are summarized using the example of indicative blocks, and satisfying the consistency ratio condition $(\mathrm{CR}<10 \%)$. 
The dispersion feature of expert opinions, reflected in the rank dispersion indicators, testifies to the stable consistency of assessments of such positions as organizing technological processes and ensuring labor efficiency. A significant divergence of opinions is observed regarding the place of indicative block of planning the development of competitive advantages in the system of development indicators of the regional agro-food industry enterprises (Table 2).

Table 1. Determination of a ranked number of indicative development blocks of the regional agrofood industry enterprises (according to the first expert assessments).

\begin{tabular}{|c|c|c|c|c|c|c|c|c|c|}
\hline \multicolumn{6}{|c|}{ Indicative blocks } & \multirow{2}{*}{$\begin{array}{l}\text { Geomet } \\
\text { ric } \\
\text { mean of } \\
\text { expert } \\
\text { assessm } \\
\text { ents } \\
\end{array}$} & \multirow{2}{*}{$\begin{array}{l}\text { Indicator } \\
\text { weight } \\
\text { factors } \\
\text { (normaliz } \\
\text { ed priority } \\
\text { vector) } \\
\end{array}$} & \multirow[b]{2}{*}{$\lambda_{\mathrm{ij}}$} & \multirow[b]{2}{*}{ Rank } \\
\hline & 1 & 2 & 3 & 4 & 5 & & & & \\
\hline $\begin{array}{l}\text { 1. Planning the } \\
\text { development of } \\
\text { competitive } \\
\text { advantages of } \\
\text { products made by } \\
\text { the processing } \\
\text { enterprises of the } \\
\text { regional AIC }\end{array}$ & 1 & 1 & 0.500 & 1 & 1 & 0.758 & 0.139 & 0.972 & 4 \\
\hline $\begin{array}{l}\text { 2. Information } \\
\text { and analytical } \\
\text { decision-making } \\
\text { support by the } \\
\text { management of } \\
\text { processing } \\
\text { enterprises of the } \\
\text { regional AIC }\end{array}$ & 1 & 1 & 0.250 & 0.500 & 0.333 & 0.530 & 0.097 & 1.067 & 5 \\
\hline $\begin{array}{l}\text { 3. Organization of } \\
\text { technological } \\
\text { processes at the } \\
\text { processing } \\
\text { enterprises of the } \\
\text { regional AIC }\end{array}$ & 2 & 4 & 1 & 2 & 1 & 1.741 & 0.319 & 1.036 & 1 \\
\hline $\begin{array}{l}\text { 4. Ensuring labor } \\
\text { efficiency at the } \\
\text { processing } \\
\text { enterprises of the } \\
\text { regional AIC }\end{array}$ & 1 & 2 & 0.500 & 1 & 1 & 1.000 & 0.183 & 1.007 & 3 \\
\hline $\begin{array}{l}\text { 5. Modernization } \\
\text { and development } \\
\text { level of the } \\
\text { material and } \\
\text { technical } \\
\text { resources of the } \\
\text { processing } \\
\text { enterprises of the } \\
\text { regional AIC }\end{array}$ & 2 & 3 & 1 & 1 & 1 & 1.431 & 0.262 & 1.005 & 2 \\
\hline Total & 7.000 & 11.00 & 3.250 & 5.500 & 3.833 & 5.460 & 1.000 & 5.087 & $\mathrm{x}$ \\
\hline Consistency index & & & & & & & & 0.022 & $\mathrm{x}$ \\
\hline Consistency ration & & & & & & & & 2.0 & $\mathrm{x}$ \\
\hline
\end{tabular}


An ordered sample matrix of expert assessments of indicative development blocks of the regional agro-food industry enterprises is specified in the form of Table 3.

As a result of a series of iterations of the expert survey with a confidence level of 0.99 and $X_{\ni}^{2}=10.2>X_{T}^{2}=9.21$ for indicative blocks to assess the development of the regional agro-food industry enterprises, the value of the modified concordance coefficient was obtained $K_{\text {кон м }}=0.729$. Using similar calculations, sampling matrices are formed within the individual blocks of development indicators of the regional agro-food industry enterprises, the corresponding modified concordance coefficients and reliability criteria are determined.

Based on the results obtained, the weight functions of structural elements were calculated in the complex indicator (Table 4).

Table 2. Ranking of indicative development blocks of the regional agro-food industry enterprises.

\begin{tabular}{|c|c|c|c|c|c|c|c|c|c|c|}
\hline \multirow[b]{2}{*}{ Indicative blocks } & \multicolumn{7}{|c|}{ Experts } & \multirow{2}{*}{$\begin{array}{c}\text { Mean rank } \\
\text { (assessment) } \\
\left(\mathbf{M}_{\mathrm{i}}\right)\end{array}$} & \multirow{2}{*}{$\begin{array}{c}\text { Range of } \\
\text { assessments, } \\
\text { score }\end{array}$} & \multirow{2}{*}{$\begin{array}{l}\text { Dispersion of } \\
\text { ranks } \\
\text { (assessments) }\end{array}$} \\
\hline & 1 & 2 & 3 & 4 & 5 & 6 & 7 & & & \\
\hline $\begin{array}{l}\text { 1. Planning the } \\
\text { development of } \\
\text { competitive } \\
\text { advantages of } \\
\text { products made by } \\
\text { the processing } \\
\text { enterprises of the } \\
\text { regional AIC }\end{array}$ & 4 & 4 & 4 & 5 & 1 & 5 & 4 & 3.857 & 4 & 1.8 \\
\hline $\begin{array}{l}\text { 2. Information and } \\
\text { analytical decision- } \\
\text { making support by } \\
\text { the management of } \\
\text { processing } \\
\text { enterprises of the } \\
\text { regional AIC }\end{array}$ & 5 & 3 & 5 & 3 & 4 & 3 & 3 & 3.714 & 2 & 0.9 \\
\hline $\begin{array}{l}\text { 3. Organization of } \\
\text { technological } \\
\text { processes at the } \\
\text { processing } \\
\text { enterprises of the } \\
\text { regional AIC }\end{array}$ & 1 & 1 & 1 & 1 & 2 & 1 & 1 & 1.143 & 1 & 0.1 \\
\hline $\begin{array}{l}\text { 4. Ensuring labor } \\
\text { efficiency at the } \\
\text { processing } \\
\text { enterprises of the } \\
\text { regional AIC } \\
\end{array}$ & 3 & 2 & 2 & 2 & 3 & 2 & 2 & 2.286 & 1 & 0.2 \\
\hline $\begin{array}{l}\text { 5. Modernization } \\
\text { and development } \\
\text { level of the material } \\
\text { and technical } \\
\text { resources of the } \\
\text { processing } \\
\text { enterprises of the } \\
\text { regional AIC }\end{array}$ & 2 & 5 & 3 & 4 & 5 & 4 & 5 & 4.000 & 3 & 1.3 \\
\hline
\end{tabular}


Table 3. Ordered matrix of a sample of expert assessments of indicative development blocks of the regional agro-food industry enterprises.

\begin{tabular}{|c|c|c|c|c|c|}
\hline \multirow{2}{*}{ Indicators } & \multicolumn{5}{|c|}{ Indicative blocks } \\
\cline { 2 - 6 } & 3 & 4 & 2 & 1 & 5 \\
\hline $\mathrm{M}_{\mathrm{i}}$ & 1.143 & 2.286 & 3.714 & 3.857 & 4.000 \\
\hline $\mathrm{Y}_{\mathrm{i}}$ & 1 & 2 & 3 & 4 & 5 \\
\hline
\end{tabular}

Thus, the vector of weight coefficients of indicative blocks to assess the development of the regional agro-food industry enterprises is specified in the form $\mathrm{Q}_{\mathrm{i}}, \mathrm{e} 0(0.118 ; 0.123$; $0.440 ; 0,205 ; 0.114)$. For particular indicators, the following weight function values were obtained:

a) on the block "planning the development of competitive advantages" $\mathrm{Q}_{\mathrm{i}}$, e1 (0.394; $0.273 ; 0.136 ; 0.197)$;

b) on the block "information and analytical decision-making support" $\mathrm{Q}_{\mathrm{i}}, \Pi 2$ (0.248; $0.166 ; 0.435 ; 0.151)$;

c) on the block "organization of technological processes" $\mathrm{Q}_{\mathrm{i}}, \mathrm{e} 3(0.473 ; 0.174 ; 0.132$; $0.221)$

d) on the block "ensuring labor efficiency" $\mathrm{Q}_{\mathrm{i}}, \mathrm{e} 4(0.241 ; 0.392 ; 0.120 ; 0.149)$;

e) on the block "modernization and development level of the material and technical resources" $\mathrm{Q}_{\mathrm{i}}$,e5 (0.138; 0.164; 0.314; 0.384).

The synthesis results of criteria hierarchy in the form of an integral priority vector are specified in Table 5.

Table 4. Calculation of the weight indicators of indicative development blocks of the regional agrofood industry enterprises.

$\begin{array}{|c|c|c|}\hline & \multicolumn{2}{|c|}{\text { Indicators }} \\$\cline { 2 - 3 }$\left.\left(\mathrm{Q}_{\mathrm{i}}, \mathrm{e} 0\right)\end{array}\right)$


The generated structure of the complex indicator is subordinated to the construction logic of a questionnaire for assessing the actual development level of the regional agro-food industry enterprises. According to the ranking methodology using a ten-point dichotomous scale of polar profiles, the experts were asked to choose an assessment that is more consistent with the state of qualifying positions of the questionnaire relevant for the Republic of Crimea, in the interval between two opposite gradations. Verbally, the extreme feature values are specified in the form of the following definitions: "completely inconsistent" (1 point) and "completely consistent" (10 points).

Using the data specified in Table 5 and the processed results of the feature ranking approach according to the dichotomous scale of polar profiles, obtained by interviewing experts, it becomes possible to single out one parameter that quantitatively characterizes the actual development level of the regional agro-food industry enterprises. According to the results, its value is 3.894 , which corresponds to an assessment below the average potential level. Generalized estimates $\left(\mathrm{V}_{\mathrm{i}}\right)$ in the context of indicative blocks and partial criteria of a complex indicator are specified in Table 6. The problem priority level (Hi) is also determined.

The decisive role in solving the problems of the regional agro-food industry development at the macro level and its coordination with the internal regime of enterprises belongs to the state bodies of legislative and executive power.

In contrast to the actions of individual processing enterprises, the state policy in the field of ensuring industrial and regional development is more consistent and should serve as the main means of stimulating and coordinating positive changes at all administration levels.

Table 5. The significance vector of the structural elements of the integrated development indicator of the regional agro-food industry enterprises.

\begin{tabular}{|c|c|}
\hline Criterion & $\begin{array}{c}\text { Weight } \\
\text { coefficient } \\
\left(\mathrm{P}_{\mathrm{i}}\right)\end{array}$ \\
\hline $\begin{array}{c}\text { 1 } \\
\text { of the regional AIC }\end{array}$ & 2 \\
\hline $\begin{array}{c}\text { Comprehensive criterion for assessing the evelopment of processing enterprises } \\
\text { processing enterprises of the regional AIC }\end{array}$ & 1.000 \\
\hline $\begin{array}{c}\text { 1.1. Availability of the development strategy for competitive advantages } \\
\text { 1.2. Application of the targeted comprehensive development program }\end{array}$ & 0.118 \\
\hline 1.3. Production program adaptation to market requirements & 0.047 \\
\hline 1.4. Application of the scenario planning technology & 0.016 \\
\hline 2. Information and analytical decision-making support by the management of \\
processing enterprises of the regional AIC & 0.023 \\
\hline 2.1. Organization of management accounting & 0.123 \\
\hline 2.2. Market state monitoring & 0.031 \\
\hline 2.3. Organization of causal analysis & 0.020 \\
\hline 2.4. Exchange of experience and attraction of consultants & 0.054 \\
\hline 3.1. The level of mastering advanced technologies & 0.019 \\
\hline r. Organization of technological processes at the processing enterprises of the & 0.440 \\
\hline
\end{tabular}




\begin{tabular}{|c|l|}
\hline 3.2. Share of innovative products & 0.077 \\
\hline 3.3. Cost and material efficiency & 0.058 \\
\hline 3.4. Scientific validity of the organization of technological processes & 0.097 \\
\hline 4. Ensuring labor efficiency at the processing enterprises of the regional AIC & 0.205 \\
\hline $\begin{array}{c}\text { 4.1. Coordination of actions of the employees and departments in solving } \\
\text { problems }\end{array}$ & 0.049 \\
\hline 4.2. The level of social and professional competence of the employees & 0.080 \\
\hline 4.3. Improving competence of the employees & 0.025 \\
\hline 4.4. Material and non-material incentives for labor results & 0.031 \\
\hline 4.5. Ensuring ergonomic workplaces and favorable psychological climate & 0.020 \\
\hline 5. Modernization and development level of the material and technical resources \\
of the processing enterprises of the regional AIC & 0.114 \\
\hline 5.1. Efficiency of engineering infrastructure usage & 0.016 \\
\hline 5.2. Innovation rate & 0.019 \\
\hline 5.3. Minimizing the environmental impact of production & 0.036 \\
\hline 5.4. Depreciation rate of fixed assets & 0.044 \\
\hline
\end{tabular}

Table 6. Assessment of the priority of development problems of the regional agro-food industry enterprises.

\begin{tabular}{|c|c|c|c|c|}
\hline $\begin{array}{c}\text { Indicator block, } \\
\text { private indicator }\end{array}$ & $\begin{array}{c}\text { Current level } \\
\text { assessment, point }\end{array}$ & $\begin{array}{c}\text { Generalized } \\
\text { estimate }\left(\mathrm{V}_{\mathrm{i}}\right)\end{array}$ & $\begin{array}{c}\text { \% of potential } \\
\text { maximum }\end{array}$ & $\begin{array}{c}\text { Problem priority } \\
\left(\mathrm{H}_{\mathrm{i}}\right)\end{array}$ \\
\hline 1. & 8.700 & 0.235 & 19.88 & 0.948 \\
\hline 1.1. & 1.9 & 0.089 & 19 & 0.378 \\
\hline 1.2. & 1 & 0.032 & 10 & 0.290 \\
\hline 1.3. & 2.9 & 0.047 & 29 & 0.115 \\
\hline 1.4. & 2.9 & 0.068 & 29 & 0.165 \\
\hline 2. & 11.130 & 0.315 & 25.59 & 0.916 \\
\hline 2.1. & 2.53 & 0.077 & 25.3 & 0.228 \\
\hline 2.2. & 4.4 & 0.090 & 44 & 0.114 \\
\hline 2.3. & 2 & 0.107 & 20 & 0.428 \\
\hline 2.4. & 2.2 & 0.041 & 22 & 0.145 \\
\hline 3. & 18.400 & 2.198 & 50.02 & 2.197 \\
\hline 3.1. & 5.8 & 1.205 & 58 & 0.873 \\
\hline 3.2. & 1.9 & 0.145 & 19 & 0.620 \\
\hline 3.3. & 4.9 & 0.285 & 49 & 0.297 \\
\hline 3.4. & 5.8 & 0.562 & 58 & 0.407 \\
\hline 4. & 19.210 & 0.902 & 43.97 & 1.149 \\
\hline 4.1. & 2.8 & 0.138 & 28 & 0.356 \\
\hline 4.2. & 6.7 & 0.538 & 67 & 0.265 \\
\hline 4.3. & 3.41 & 0.084 & 34.1 & 0.163 \\
\hline 4.4. & 1.4 & 0.043 & 14 & 0.263 \\
\hline 4.5. & 4.9 & 0.098 & 49 & 0.102 \\
\hline 5. & 9.800 & 0.243 & 21.35 & 0.896 \\
\hline 5.1 & 4.9 & 0.077 & 49 & 0.080 \\
\hline & & & & \\
\hline & & & & \\
\hline
\end{tabular}




\begin{tabular}{|c|c|c|c|c|}
\hline 5.2. & 1 & 0.019 & 10 & 0.169 \\
\hline 5.3 & 2.9 & 0.104 & 29 & 0.254 \\
\hline 5.4. & 1 & 0.044 & 10 & 0.393 \\
\hline $\begin{array}{c}\text { Total } \\
\text { (by blocks) }\end{array}$ & $\mathrm{X}$ & 3.894 & 38.938 & $\mathrm{X}$ \\
\hline
\end{tabular}

Within the framework of the multi-parameter approach used, it should be noted that, considering the state's influence on the processes of the regional agro-food industry development, we mean both its direct (within the powers of the authorities) and its indirect forms - the influence on the initiative of society, as well as the involvement of entities with the relatively large powers and resources. Thus, the public administration of development determines the scale of a number of forms of managerial influences from other entities.

An important element of public administration of the regional agro-food industry development is a multi-level information exchange that can expand and totally rebuild the system connections. The implementation of the desired changes is determined by the capabilities of the existing material and technical resources, the availability of financial resources and the boundaries of regulatory and legal field. The designated structural components form the first, second and third blocks of assessment indicators, respectively (Fig. 2).

For a comprehensive study of the subject area problems and a search for ways to eliminate them, one should also consider the state of planning, public administration and monitoring, represented by the groups of indicators of the fourth and fifth blocks, respectively.

The criteria for the public administration level of the regional agro-food industry development, combined in the sixth indicative block, serve to track changes directly in the organization of processes.

Additive folding of the proposed indicators and their blocks, taking into account the weights established by experts and the modern levels of individual elements, allows setting the complex indicator value.

Table 7. Assessment of the priority of the public administration problems in the regional agro-food industry development.

\begin{tabular}{|c|c|c|c|c|c|}
\hline $\begin{array}{c}\text { Indicator } \\
\text { block, } \\
\text { private } \\
\text { indicator }\end{array}$ & $\begin{array}{c}\text { Weight } \\
\text { coefficient } \\
\left(\mathrm{P}_{\mathrm{i}}\right)\end{array}$ & $\begin{array}{c}\text { Current level } \\
\text { assessment, } \\
\text { point }\end{array}$ & $\begin{array}{c}\text { Generalized } \\
\text { estimate }\left(\mathrm{V}_{\mathrm{i}}\right)\end{array}$ & $\begin{array}{c}\text { \% of potential } \\
\text { maximum }\end{array}$ & $\begin{array}{c}\text { Problem } \\
\text { priority }\left(\mathrm{H}_{\mathrm{i}}\right)\end{array}$ \\
\hline 1. & 0.190 & 14.000 & 0.621 & 32.64 & 1.282 \\
\hline 1.1. & 0.047 & 5 & 0.236 & 50 & 0.236 \\
\hline 1.2. & 0.083 & 2 & 0.165 & 20 & 0.661 \\
\hline 1.3. & 0.033 & 5 & 0.165 & 50 & 0.165 \\
\hline 1.4. & 0.028 & 2 & 0.055 & 20 & 0.220 \\
\hline 2. & 0.087 & 9.000 & 0.191 & 22.12 & 0.674 \\
\hline 2.1. & 0.034 & 1 & 0.034 & 10 & 0.307 \\
\hline 2.2. & 0.017 & 3 & 0.051 & 30 & 0.119 \\
\hline 2.3. & 0.024 & 4 & 0.094 & 40 & 0.142 \\
\hline 2.4. & 0.012 & 1 & 0.012 & 10 & 0.106 \\
\hline 3. & 0.408 & 23.000 & 2.366 & 57.99 & 1.714 \\
\hline 3.1. & 0.190 & 6 & 1.138 & 60 & 0.758 \\
\hline 3.2. & 0.053 & 4 & 0.212 & 40 & 0.319 \\
\hline 3.3. & 0.102 & 5 & 0.510 & 50 & 0.510 \\
\hline 3.4. & 0.063 & 8 & 0.506 & 80 & 0.126 \\
\hline 4. & 0.143 & 24.000 & 0.903 & 63.27 & 0.524 \\
\hline 4.1. & 0.024 & 8 & 0.192 & 80 & 0.048 \\
\hline
\end{tabular}




\begin{tabular}{|c|c|c|c|c|c|}
\hline 4.2. & 0.069 & 7 & 0.481 & 70 & 0.206 \\
\hline 4.3. & 0.020 & 4 & 0.080 & 40 & 0.120 \\
\hline 4.4. & 0.030 & 5 & 0.150 & 50 & 0.150 \\
\hline 5. & 0.077 & 11.000 & 0.268 & 34.73 & 0.504 \\
\hline 5.1 & 0.029 & 4 & 0.116 & 40 & 0.173 \\
\hline 5.2. & 0.010 & 1 & 0.010 & 10 & 0.094 \\
\hline 5.3 & 0.012 & 1 & 0.012 & 10 & 0.106 \\
\hline 5.4. & 0.026 & 5 & 0.130 & 50 & 0.130 \\
\hline 6. & 0.095 & 24.000 & 0.572 & 60.14 & 0.379 \\
\hline 6.1. & 0.037 & 6 & 0.224 & 60 & 0.149 \\
\hline 6.2. & 0.015 & 8 & 0.122 & 80 & 0.031 \\
\hline 6.3. & 0.028 & 6 & 0.168 & 60 & 0.112 \\
\hline 6.4. & 0.015 & 4 & 0.058 & 40 & 0.088 \\
\hline $\begin{array}{c}\text { Total } \\
\text { (by blocks) }\end{array}$ & 1.000 & $\mathrm{X}$ & 4.923 & 49.23 & $\mathrm{X}$ \\
\hline
\end{tabular}

As a result, the vector of weight coefficients of indicative blocks has the following form: $\mathrm{Q}_{\mathrm{i}}, \mathrm{g} 0(0.190 ; 0.087 ; 0.408 ; 0.143 ; 0.077 ; 0.095)$. The values of the weight functions of particular indicators are:

a) on the block "information, consulting and research support for development" $\mathrm{Q}_{\mathrm{i}}$ ,g1 (0.047; 0.083; 0.033; 0.028);

b) on the block "material, technical, financial and credit support for development" $\mathrm{Q}_{\mathrm{i}}$ ,g2 (0.034; 0.017; 0.024; 0.012);

c) on the block "legal regulation of development" $\mathrm{Q}_{\mathrm{i}}, \mathrm{g} 3(0.190 ; 0.053 ; 0.102 ; 0.063)$;

d) on the block "state control and monitoring" $\mathrm{Q}_{\mathrm{i}}, \mathrm{g} 4(0.024 ; 0.069 ; 0.020 ; 0.030)$;

e) on the block "planning and forecasting of development" $\mathrm{Q}_{\mathrm{i}}, \mathrm{g} 5(0.029 ; 0.010$; $0.012 ; 0.026$ );

f) on the block "administrative and organizational structure of the public administration system for development" $\mathrm{Q}_{\mathrm{i}}, \mathrm{g} 6(0.037 ; 0.015 ; 0.028 ; 0.015)$.

The priority parameter that determines the public administration level of the processing industry development of the regional AIC is the nature of legal regulation $\left(\mathrm{P}_{\mathrm{i}}=0.408\right)$, with the decisive influence of public administration in the field of import substitution $\left(\mathrm{P}_{\mathrm{i}}=\right.$ 0.190). The second important indicator is information, consulting and research support $\left(\mathrm{P}_{\mathrm{i}}=\right.$ $0.190)$, with the fundamental role of increasing the research support level $\left(\mathrm{P}_{\mathrm{i}}=0.083\right)$. The public administration and monitoring of development occupies the third priority position $\left(\mathrm{P}_{\mathrm{i}}\right.$ $=0.143)$ with the primary importance of food safety control $\left(\mathrm{P}_{\mathrm{i}}=0.069\right)$.

The administrative and organizational structure of the development public administration system $\left(\mathrm{P}_{\mathrm{i}}=0.095\right)$, material, technical, financial and credit support $\left(\mathrm{P}_{\mathrm{i}}=\right.$ $0.087)$, as well as planning and forecasting of development $\left(\mathrm{P}_{\mathrm{i}}=0.077\right)$ are close in terms of the influence level on the complex indicator value. Among the indicators of these groups, the leading positions are taken by the following ones: improving interaction between the processing organizations and the raw material producers $\left(\mathrm{P}_{\mathrm{i}}=0.037\right)$, creating facilities on the basis of public-private partnership, direct state investment in the industrial and logistics facilities $\left(\mathrm{P}_{\mathrm{i}}=0.034\right)$ and the depth of elaboration of the federal and regional development programs $\left(\mathrm{P}_{\mathrm{i}}=0.029\right)$.

Integration of the results obtained and expert assessments (on a dichotomous scale) of the current level of the corresponding indicators made it possible to establish the complex indicator value characterizing the current state of public administration of the regional agrofood industry development (Table 7). Its value, which is 4.23 points, testifies to the insufficient attention of the state authorities to the problems existing in the studied area. 


\section{Discussion}

Taking into account the results of the above calculations, according to experts, the strongest influence on the development of the regional agro-food industry enterprises is made by the technological process organization features $\left(\mathrm{P}_{\mathrm{i}}=0.440\right)$, where the priority is given to the development level of advanced technologies $\left(P_{i}=0.208\right)$. The second important tool, which influences the development of the regional agro-food industry enterprises is ensuring labor efficiency $\left(\mathrm{P}_{\mathrm{i}}=0.205\right)$, while the greatest positive effect is expected from increasing the social and professional competence of the employees $\left(\mathrm{P}_{\mathrm{i}}=0.080\right)$. Planning the development of competitive advantages $\left(\mathrm{P}_{\mathrm{i}}=0.118\right)$, information and analytical decisionmaking support $\left(\mathrm{P}_{\mathrm{i}}=0.123\right)$, as well as modernization and development level of the material and technical resources $\left(P_{i}=0.114\right)$ are close in terms of the influence level on the integral indicator value. Among the indicators of these groups, the leading positions are occupied by the following ones: organization of cause-and-effect analysis $\left(\mathrm{P}_{\mathrm{i}}=0.054\right)$, availability of the development strategy for competitive advantages $\left(\mathrm{P}_{\mathrm{i}}=0.047\right)$, depreciation rate of fixed assets $\left(\mathrm{P}_{\mathrm{i}}=0.044\right)$.

A significant problem for most enterprises is the prevailing lack of a clear development strategy for competitive advantages (1.9 points). Due to the low level of the "Development planning" block values (less than 3 points) in different time ranges, the internal and external inconsistency of management and production processes for ensuring development of the regional agro-food industry enterprises and uncertainty are increasing.

Among the elements of the "Information and analytical decision-making support" indicative block, the organization of cause-and-effect analysis should be noted as the most important, the level of which does not correspond to the modern requirements for the industrial production development ( 2 points) and is the lowest in the group. At the same time, due to the improper organization of information support processes, the decisionmaking base is underdeveloped, there is a shortage of relevant information about the course of business processes at the processing enterprises (2.53 points) and market dynamics (4.4 points), which hinders the implementation of the analytical function.

Among the indicators characterizing the organizational side of ensuring development of the regional agro-food industry enterprises, the highest score (5.8 points) was assigned to the level of mastering advanced technologies. At the same time, this position is the main problem $\left(\mathrm{H}_{\mathrm{i}}=0.873\right)$ both within the indicative block and the entire system of indicators, which indicates the still inappropriate organization level of technological processes to ensure development of the regional agro-food industry enterprises. It should be noted that the tendency is aggravating as the progressive technologies appear and are introduced into the international practice, which, due to the low innovative activity of Crimean manufacturers, weakens their competitive positions.

Among the elements of the fourth indicative block, the priority improvement is required by the coordination of actions of the employees and departments in solving problems (2.8 points). In addition, the experts recognize the average level of social and professional competence of personnel (6.7 points) with an insufficiently intensive increase (3.41 points). A high level of labor efficiency can be ensured only with the appropriate motivation of the employees, which, due to the insufficient material and non-material (1.4 points) incentives, is a factor limiting the implementation of labor potential.

According to experts, the modernization and development level of the material and technical resources of the regional agro-food industry enterprises is primarily expressed in the depreciation rate of fixed assets ( 1 point), the effective functioning of which in the progressive world practice is of decisive importance at all food production stages. Adequate use of the engineering infrastructure (4.9 points) and satisfactory environmental impact (2.9 
points, priority 0.254 ) are not a sufficient condition and are not able to compensate for the required extent of innovation implementation (1 point, priority 0.169 ).

The construction of a ranked number of priority development problems of the regional agro-food industry enterprises makes it possible to systematize the priority areas of its increase in the following sequence $\left(\mathrm{H}_{\mathrm{i}}\right)$ :

1. 3.1. The level of mastering advanced technologies (0.873);

2. 3.2. Share of innovative products $(0.620)$;

3. 2.3. Organization of cause-and-effect analysis (0.428);

4. 3.4. Scientific validity of the organization of technological processes (0.407);

5. 5.4. Depreciation rate of fixed assets (0.393);

6. 1.1. Availability of the development strategy for competitive advantages (0.378);

7. 4.1. Coordination of actions of the employees and departments in solving problems $(0.356)$;

8. 3.3. Cost and material efficiency (0.297).

Four out of nine problem areas relate to the subject area of organizing technological processes at the regional agro-food industry enterprises, two - to planning the development of competitive advantages, one each - to the information and analytical decision-making support by the management of the regional agro-food industry enterprises, ensuring labor efficiency, modernization and level development of the material and technical resources of the regional agro-food industry enterprises.

The identified bottlenecks reflect only the general situation in the region. An individual priority rank of development problems, which is different from the one obtained from the research results, can be built for the specific processing enterprises.

Considering the results of calculations based on expert assessments of the state regulation level of the regional agro-food industry development, the following features can be distinguished. The most bottlenecks were identified in the field of legal regulation of development and lie in the insufficiently effective state regulation of import substitution, insufficient stimulation of demand for domestic products of the processing industry of the regional AIC, insufficiently effective state regulation in the field of import substitution $\left(\mathrm{H}_{\mathrm{i}}\right.$ $=0.758$ and 0.319 , respectively), as well as insufficient state incentives for the production of high-quality domestic products $\left(\mathrm{H}_{\mathrm{i}}=0.510\right)$. In turn, this forms a weak basis for the industry's innovative and technological development. Among the priority problems of the "information, consulting and research support for development" block, it is necessary to note the insufficient level of research support $\left(\mathrm{H}_{\mathrm{i}}=0.661\right)$. In the "material, technical, financial and credit support for development" block, the priority measures are required by the development of production capacities on the basis of public-private partnerships, direct government investments and creation of unitary enterprises $\left(\mathrm{H}_{\mathrm{i}}=0.307\right)$.

\section{Conclusions}

The relationship and sequence of solving priority problems of the regional agro-food industry development, dominating at the micro and macro levels (the coefficient value exceeds 0.3 ), can be specified in the form of a graph (Fig. 4). 


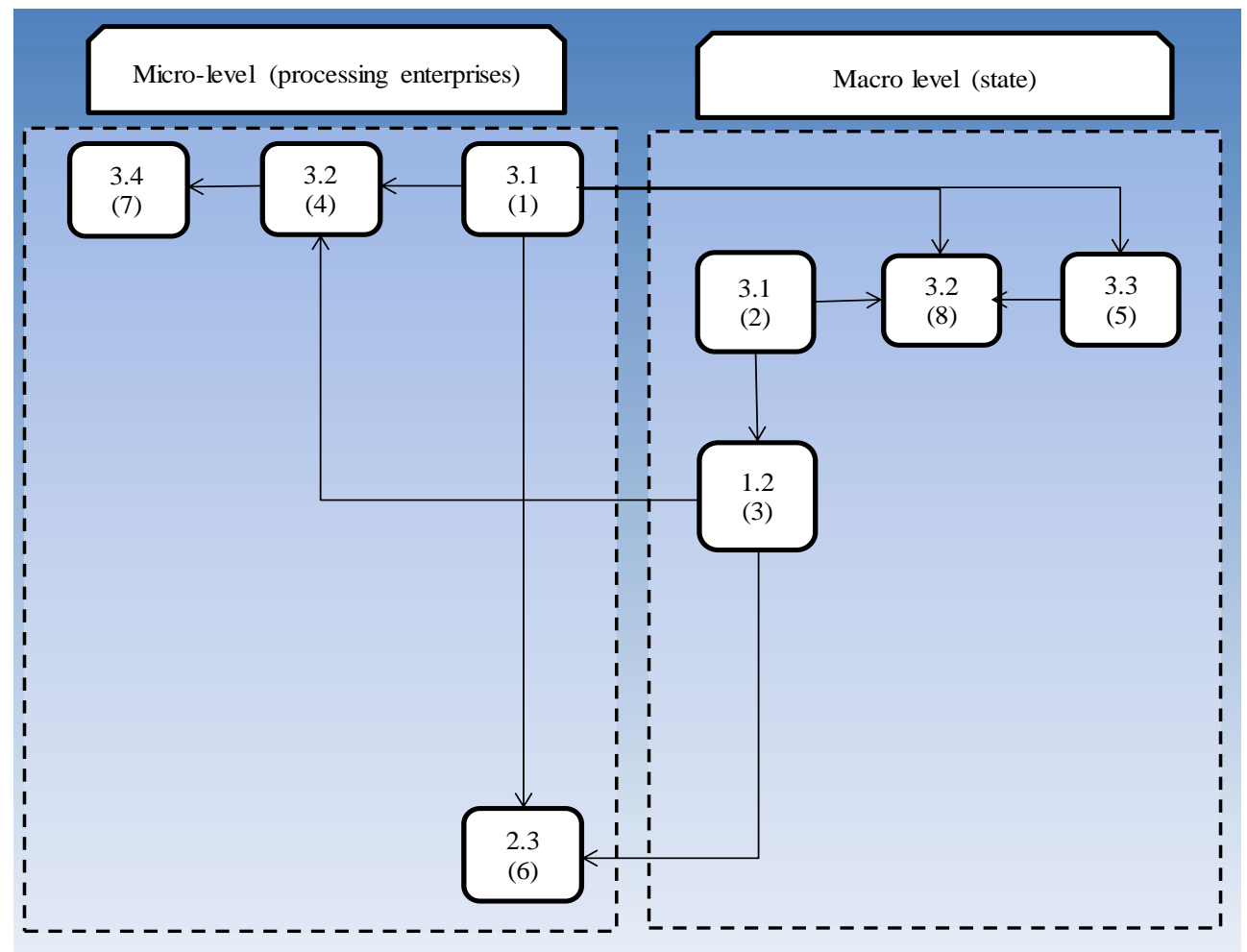

Fig. 4. Graph of priority problems of the regional agro-food industry development.

The basis of constructive changes in the management of the regional agro-food industry development should be the activation of manufacturers' activities in the development of advanced technologies with the provision of scientific substantiation of the organization of technological processes, a desire to increase the share of innovative products. A systematic causal analysis will ensure the integrity and continuity of development.

State regulation in the field of import substitution is an integral condition. At the same time, it is necessary to stimulate the quality of domestic products and demand for them, which also requires the development of research support.

Elimination of the identified dominant problems will ensure the dynamic and sustainable development of the regional agro-food industry, increase the competitiveness of national producers and implement the constitutional right of the population to consume the high-quality and healthy food products made from their own raw materials.

The identified bottlenecks determine the subject area of further actions in terms of developing recommendations to ensure the regional agro-food industry development in the long and medium term.

\section{References}

1. Singh R K, Murty H R, Gupta S K, Dikshit A K 2012 An overview of sustainability assessment methodologies Ecological Indicators 15(1) 281-99

2. Patton M Q 2012 Essentials of utilization-focused evaluation (Thousand Oaks: Sage Publications)

3. Aubin J, Donnars C, Supkova M, Dorin B, Gaillard G, Garcia F et al 2013 N Food system sustainability: Insights from duALIne ed C Esnouf, M Russel and N Bricas 
(Cambridge: Cambridge University Press) chapter "A critical panorama of methods used to assess food sustainability" pp 198-232

4. Popov E V, Veretennikova A Y, Omonov Z K 2017 A social innovation impact assessment matrix Digest Finance 22(4) 365-78 https://doi.org/ 10.24891/re.15.9.1752

5. Dhondt S, Van de Ven H, Ziauberyte R, Van der Torre W, Cressey P, Kaderabkova A et al 2016 Ex-ante impact assessment \& value network analysis for SI. Gelsenkirchen (Institute for Work and Technology Available) at: https://repository.tudelft.nl/view/tno/uuid\%3A843a0c44-4e02-4213-9ff5b03b0ff081d6

6. Wiek A, Kay B, Forrest N 2017 Urban sustainability transitions ed F De Niki, D Loorbach, V Castán Broto and L Coenen (New York: Taylor \& Francis) chapter 14 "Worth the trouble?! An evaluative scheme for urban sustainability transition labs (USTLs) and an application to the USTL in Phoenix, Arizona" pp 227-56

7. Luederitz C, Schäpke N, Wiek A, Lang D J, Bergmann M, Bos J J et al 2017 Learning through evaluation: A tentative evaluative scheme for sustainability transition experiments J. of Cleaner Production 169 61-76 Available at: https://doi.org/10.1002/9781119171386.ch3.

8. Peterson M 2006 The precautionary principle is incoherent Risk Analysis 26(3) 595601 Available at: https://doi.org/10.1111/j.1539-6924.2006.00781.x.

9. Leach M, Scoones I, Stirling A 2010 Dynamic sustainabilities: Technology, environment, social justice (Washington: Earthscan)

10. Naudet J, Delarue J, Bernard T 2012 Impact evaluations: A tool for accountability? Lessons from experience in AFD J. of Development Effectiveness 20(4) 27-48 Available at: doi:10.3917/edd.264.0027.

11. Howarth R B, Norgaard R B 2013 Intergenerational Transfers and the Social Discount Rate Environmental and Resource Economics 3(4) 337-58

12. Portney P R, Weyant J P 1999 Discounting and intergenerational equity Modern Economy 10(11)

13. Mayne J 2011 Evaluating the complex: Attribution, contribution, and beyond ed $\mathrm{K}$ Forss, M Marra and R Schwartz (Piscataway: Transaction Press) chapter "Contribution analysis: Addressing cause and effect"

14. Temple L, Barret D, Blundo Canto G, Dabat M H, Devaux-Spatarakis A, Faure G, Triomphe B 2018 Assessing impacts of agricultural research for development: A systemic model focusing on outcomes Research Evaluation 27(2) 157-170 Available at: https://doi.org/10.1093/reseval/rvy005.

15. Fraser D G E, Dougill A J, Mabee W E, Reed M, McAlpine P 2005 Bottom up and top down: analysis of participatory process for sustainability indicator identification as a pathway to community empowerment and sustainable environmental management $J$. of Environmental Management 78 114-27

16. Abi-Nader J, Ayson A, Harris K, Herrera H, Eddins D, Habib D, Villanueva L 2009 Whole measures for community food systems: Values-based planning and evaluation (Burlington: Center for Whole Communities)

17. Landert J, Schader C, Moschitz H, Stolze M 2017 A holistic sustainability assessment method for urban food system governance Sustainability 9(4) 490 Available at: https://doi.org/10.3390/su9040490.

18. Carlsson L, Callaghan E, Morley A, Broman G 2017 Food system sustainability across scales: A proposed local-to-global approach to community planning and assessment 
Sustainability 9(6) 1061

19. Douthwaite B, Schulz S, Olanrewaju A S, Ellis-Jones J 2007 Impact pathway evaluation of an integrated Striga hermonthica control project in northern Nigeria Agricultural Systems 92(1-3) 201-22 Available at: https:// doi.org/10.1016/j.agsy.2006.03.007.

20. Proietti C, Wittine D, Alvarez S, Parker M, Schulte-Geldermann E, Stoian D, Thiele G 2015 Co-constructing impact pathways with stakeholders for results-based management CGIAR Research Program on Roots, Tubers and Banana Brief $\mathrm{n}^{\circ} 1$

21. Beshelev S D, Gurvich S D 1980 Mathematical and statistical methods of expert assessments Statistics 263

22. Saati T, Kerns K 1991 Analytical planning Organization of systems Radio and communication 224

23. Gmurman V E 2003 Probability theory and mathematical statistics Higher school 479

24. Gorokhova T, et al 2020 E3S Web of Conferences 16409034 doi:10.1051/e3sconf/202016409034

25. Trikoz E N 2018 Rusin 51(1) 113-133 doi:10.17223/18572685/51/9 